Acta Chemica Scandinavica A 38 (1984) 95-99

\title{
A Theoretical Study of Molecular Structure and Conformational
}

\section{Preference of 3-Aminopropionitrile}

\author{
PER N. SKANCKE
}

Department of Chemistry, Institute of Mathematical and Physical Sciences, The University of Troms $\varnothing$, P.O.Box 953, N-9001 Troms $\varnothing$, Norway

Complete geometry optimizations of five different conformers of 3-aminopropionitrile have been performed by SCF MO calculations using a split-valence basis. In contrast to the results of a very recent microwave study ${ }^{2}$ we find that four of the conformers have almost equal total energies (within $2 \mathrm{~kJ} / \mathrm{mol}$ ). Internal hydrogen bonding and other intramolecular interactions are discussed in terms of electronic populations and localized orbitals.

Some of the molecules displaying intramolecular hydrogen bonding are structurally interesting in the sense that several different conformations having almost equal energies are possible. In a recent series of papers Møllendal et al. have performed spectroscopic studies of structures and conformational equilibria of alcohols, amines, phosphines and thiols posessing internal hydrogen bonds. ${ }^{1}$ None of the reported studies included measurements on more than two isotopic species. In most of the cases recordings were made on only one species. Consequently the structural information available from these investigations is rather limited. Furthermore the precision of the geometrical and energetical data derived from these studies is often critically dependent on the assumption of some parameter values at the outset.

$A b$ initio molecular orbital calculations at the SCF level are now accepted as an important tool in the exploration of molecular structures, and by using medium sized basis sets reliable information on molecular structure may be obtained.

In the present paper we report the result of
SCF calculations of the different possible conformations of 3-aminopropionitrile. The reason for choosing this molecule is that a very recent microwave study ${ }^{2}$ including only one isotopic species was unable to account for more than two of the possible different conformations of the molecule. Furthermore the majority of structural parameters were assumed fixed leaving only two parameters free to vary in the fitting of rotational constants.

We think that SCF calculations on this molecule can complete the structurally interesting information as well as test the assumptions made in the microwave study.

\section{METHOD}

The calculations were performed using the program TEXAS written by Pulay. ${ }^{3}$ The essential feature of this program system is that energy gradients are calculated analytically, and complete geometry optimizations are carried out by the force relaxation method. ${ }^{4}$

For carbon and nitrogen we used a 4-21 Gaussian basis set ${ }^{5}$ which is similar to the $4-31 G$ basis of Pople et al. ${ }^{6}$ In the former set the valence shell contains three functions instead of four, split into two-one. In a systematic comparative study of molecular geometries using different basis sets it has been demonstrated that the performance of the economic 4-21 set is of the same quality as the larger 4-31G set. ${ }^{5}$

For hydrogen $3 s$-functions contracted to two functions were used.

In the end points reached by the geometry optimization the energy of each of the studied 


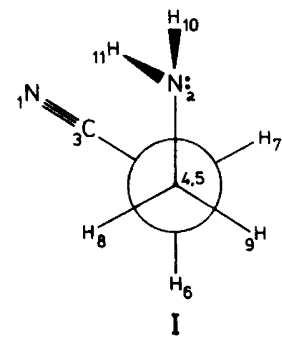

IV<smiles>CC1C2CC3(C)C(C)C(C(C#N)C13)N2C</smiles>

III

II

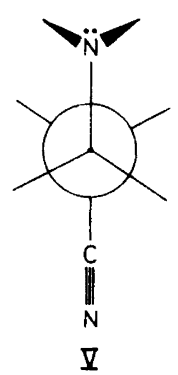

Fig. 1. Projections along the $\mathrm{C} 4-\mathrm{C} 5$ bond of the different conformers of 3-aminopropionitrile considered. Labelling of atoms given in $I$.

conformers was recalculated using 4-31G and 6-31G basis sets. This was done in order to obtain a picture of possible uncertainties in the estimated energy differences due to shortcomings of the basis sets applied.

\section{RESULTS AND DISCUSSION}

The conformers included in our study are those discussed by Møllendal et al. ${ }^{2}$ in their microwave investigation. The conformers are depicted in Fig. 1.

In the end points reached by the geometry optimizations (using a 4-21 basis ${ }^{5}$ ) total energies were also calculated using scaled 4-31G and 6-31G basis sets. ${ }^{6}$ The results of these calculations, presented in Table 1, show that conformer

Table 1. Relative energies (in $\mathrm{kJ} / \mathrm{mol}$ ) of different conformers of 3-aminopropionitrile. Numbering of conformations is given in Fig. 1.

\begin{tabular}{llllll}
\hline Basis set & I & II & III & IV & V \\
\hline 4-21 & 1.8 & 0.0 & 6.7 & 1.7 & 2.1 \\
4-31G & 1.2 & 0.0 & 5.1 & 1.3 & 1.9 \\
6-31G & 0.8 & 0.0 & 4.7 & 0.9 & 1.9 \\
\hline
\end{tabular}

II is the most stable one. However, the energy differences between conformer II and the remaining ones except III are all within $2 \mathrm{~kJ} / \mathrm{mol}$. Conformer III is unique in having somewhat higher energy. The calculated electric dipole moments, given in Table 2 , are of a substantial

Table 2. Gross atomic populations and dipole moments for different conformers of 3-aminopropionitrile. Scaled 6-31G basis.

\begin{tabular}{llllll}
\hline \multicolumn{4}{l}{ Conformer } \\
Atom & I & II & III & IV & V \\
\hline N1 & 7.324 & 7.320 & 7.322 & 7.316 & 7.313 \\
N2 & 7.844 & 7.832 & 7.841 & 7.845 & 7.837 \\
C3 & 5.884 & 5.879 & 5.848 & 5.897 & 5.889 \\
C4 & 6.304 & 6.338 & 6.316 & 6.300 & 6.333 \\
C5 & $\mathbf{6 . 1 0 3}$ & $\mathbf{6 . 1 0 0}$ & 6.100 & 6.099 & 6.088 \\
H6 & $\mathbf{0 . 7 8 7}$ & 0.783 & 0.790 & 0.788 & 0.788 \\
H7 & $\mathbf{0 . 7 6 1}$ & 0.787 & 0.788 & 0.762 & 0.788 \\
H8 & 0.841 & 0.809 & 0.813 & 0.835 & 0.807 \\
H9 & 0.817 & 0.813 & 0.842 & 0.811 & 0.807 \\
H10 & 0.671. & 0.678 & 0.664 & 0.678 & 0.675 \\
H11 & 0.662 & 0.661 & 0.676 & 0.669 & 0.675 \\
& & & & & \\
$\mu(D)$ & 4.16 & 3.63 & 5.56 & 4.40 & 4.18 \\
\hline
\end{tabular}


magnitude, indicating that all conformers should absorb in the microwave region.

In accordance with Møllendal et $a .^{2}{ }^{2}$ we find a minor energy difference between conformers I and II, and we also reproduce the observed difference between the values of the valence angle $\mathrm{N} 2 \mathrm{C} 5 \mathrm{C} 4$ in conformer I and II.

The calculated non-bonding overlap populations given in Table 3 indicate a small positive overlap between the $\mathrm{N} \equiv \mathrm{C}-$ and $-\mathrm{NH}_{2}$ groups in conformers I and II. This positive overlap may be interpreted in terms of internal hydrogen bonding between the end groups in these conformers. This interpretation is consistent with a slightly lower $\mathrm{N} 1-\mathrm{C} 3$ bond population in I and II than in the remaining conformers.

In Fig. 2 are given orbital energies for Boyslocalized ${ }^{7}$ orbitals in all the conformers studied. A slight stabilization of the nitrogen lone-pair in the $\mathrm{N} \equiv \mathrm{C}$ - group as well as of the quasi-pi bonds in this group for the most stable conformer (II) is also in conformity with an $\mathrm{H}$-bonding situation.

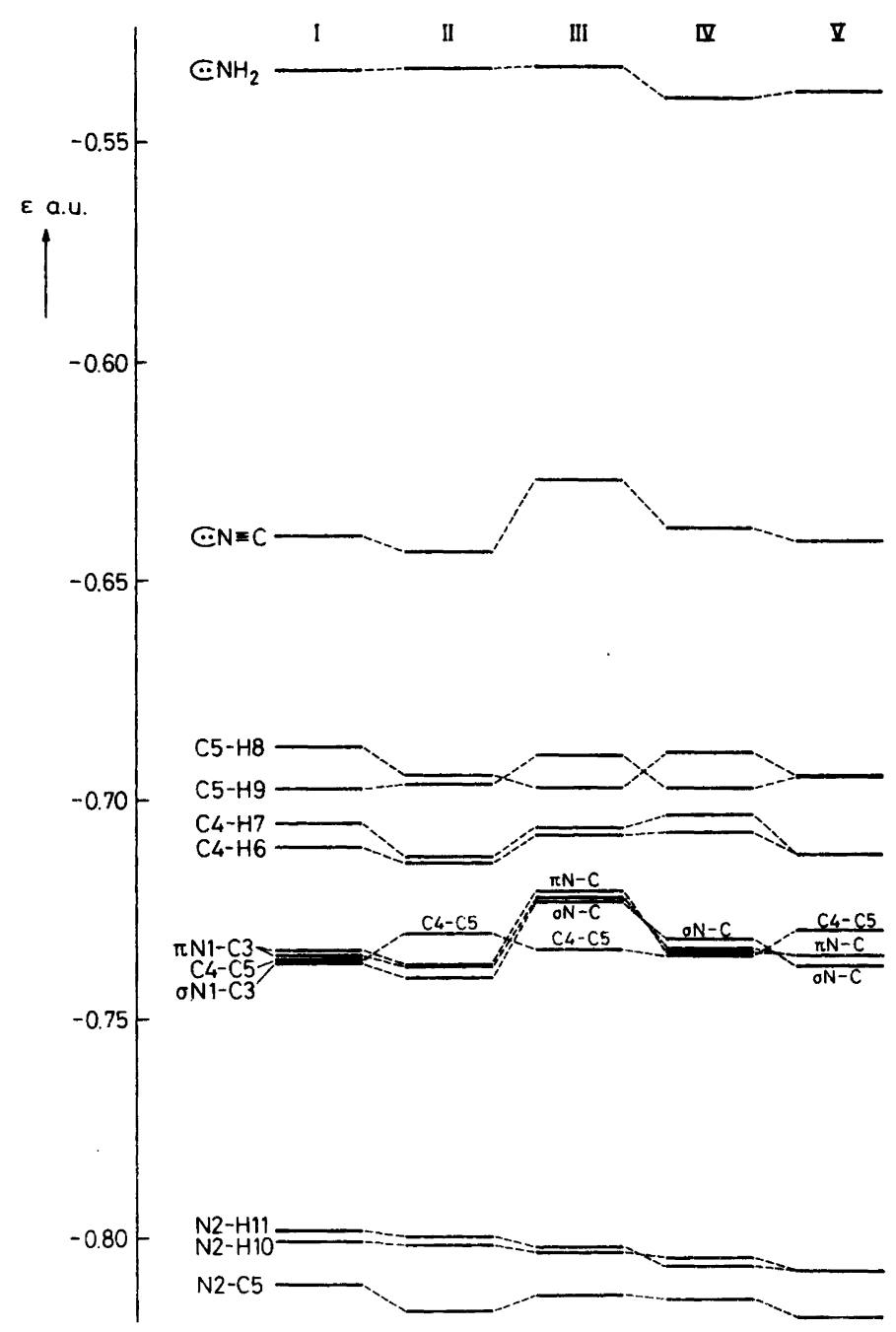

Fig. 2. Orbital energies for Boys-localized orbitals of the different conformers of 3-aminopropionitrile $\left(1\right.$ a.u. $\left.=26.255210 \cdot 10^{2} \mathrm{~kJ} / \mathrm{mol}\right)$. 
Table 3. Selected overlap populations for different conformers of 3-aminopropionitrile. Scaled 6-31G basis.

\begin{tabular}{|c|c|c|c|c|c|}
\hline \multicolumn{2}{|c|}{ Conformer I } & II & III & IV & V \\
\hline \multicolumn{6}{|c|}{ Bonded regions } \\
\hline $\begin{array}{l}\text { N1-C3 } \\
\text { C3-C4 } \\
\text { N2-C5 } \\
\text { N2-H10 } \\
\text { N2-H11 }\end{array}$ & $\begin{array}{l}1.849 \\
0.258 \\
0.444 \\
0.678 \\
0.662\end{array}$ & $\begin{array}{l}1.838 \\
0.234 \\
0.476 \\
0.675 \\
0.674\end{array}$ & $\begin{array}{l}1.857 \\
0.271 \\
0.429 \\
0.683 \\
0.669\end{array}$ & $\begin{array}{l}1.871 \\
0.144 \\
0.433 \\
0.664 \\
0.679\end{array}$ & $\begin{array}{l}1.863 \\
0.135 \\
0.449 \\
0.677 \\
0.677\end{array}$ \\
\hline
\end{tabular}

Non-bonded regions

\begin{tabular}{rrrrrr} 
N1 $\cdots H 10$ & 0.000 & 0.000 & 0.000 & 0.000 & 0.000 \\
N1 $\cdots H 11$ & 0.002 & 0.002 & 0.000 & 0.000 & 0.000 \\
C $3 \cdots H 10$ & 0.000 & -0.001 & 0.000 & 0.000 & 0.000 \\
C $3 \cdots H 11$ & 0.013 & 0.011 & 0.000 & 0.000 & 0.000 \\
\hline
\end{tabular}

Table 4. 1,3-interaction energies for different conformers of 3-aminopropionitrile. Interaction energies defined in the text. Energies in $\mathrm{kJ} / \mathrm{mol}$.

\begin{tabular}{llllll}
\hline $\begin{array}{l}\text { Con- } \\
\text { former }\end{array}$ & I & II & III & IV & V \\
\hline$E$ (int.) & +3.1 & +4.0 & -0.9 & +1.6 & +1.9 \\
\hline
\end{tabular}

In order to obtain additional information about the interaction between the end groups of the molecule, we have estimated the 1,3-interaction energies ${ }^{8}$ from the formal reaction

$$
\begin{aligned}
& \mathrm{N} \equiv \mathrm{C}-\mathrm{CH}_{2}-\mathrm{CH}_{2}-\mathrm{NH}_{2}+\mathrm{CH}_{3}-\mathrm{CH}_{3} \longrightarrow \\
& \mathrm{N} \equiv \mathrm{C}-\mathrm{CH}_{2}-\mathrm{CH}_{3}+\mathrm{CH}_{3}-\mathrm{CH}_{2}-\mathrm{NH}_{2} .
\end{aligned}
$$

These interaction energies were calculated at geometries that corresponded to optimized structures for the different conformers, and at correspondingly frozen geometries for ethane and the monosubstituted species using a 6-31G basis. Relaxation of the geometries for ethane and the monosubstituted species had a negligible effect on the relative values of the interaction energies. These values were also insensitive to basis sets applied. The values, given in Table 4 , indicate a stabilizing 1,3-interaction for all conformers except III for which there is a small destabilizing interaction.

As revealed by Fig. 1 conformer III is suffering from an interaction between the electron rich $\mathrm{N} \equiv \mathrm{C}$-region and the $\mathrm{N} 2$ lone-pair. This interaction is net destabilizing indicated by the somewhat higher total energy of this conformer. The localized orbital diagram in Fig. 2 reflects this

Table 5. Optimized values for structural parameters in different conformers of 3-aminopropionitrile. 4-21 basis. Only selected parameters included in the table. Bond lengths (R) in $\mathrm{nm}$, angles (A) in

\begin{tabular}{|c|c|c|c|c|c|}
\hline Conformer & I & II & III & IV & V \\
\hline $\begin{array}{l}R(\mathrm{~N} 1-\mathrm{C} 3) \\
R(\mathrm{C} 3-\mathrm{C} 4) \\
R(\mathrm{C} 4-\mathrm{C} 5) \\
R(\mathrm{C} 5-\mathrm{N} 2) \\
R(\mathrm{~N} 2-\mathrm{H} 10) \\
R(\mathrm{~N} 2-\mathrm{H} 11)\end{array}$ & $\begin{array}{l}0.114 \\
0.147 \\
0.154 \\
0.147 \\
0.100 \\
0.100\end{array}$ & $\begin{array}{l}0.114 \\
0.146 \\
0.156 \\
0.146 \\
0.100 \\
0.100\end{array}$ & $\begin{array}{l}0.114 \\
0.146 \\
0.154 \\
0.146 \\
0.100 \\
0.100\end{array}$ & $\begin{array}{l}0.114 \\
0.146 \\
0.154 \\
0.147 \\
0.100 \\
0.100\end{array}$ & $\begin{array}{l}0.114 \\
0.146 \\
0.156 \\
0.146 \\
0.100 \\
0.100\end{array}$ \\
\hline $\begin{array}{l}A(\mathrm{~N} 1 \mathrm{C} 3 \mathrm{C} 4) \\
A(\mathrm{C} 3 \mathrm{C} 4 \mathrm{C} 5) \\
A(\mathrm{C} 4 \mathrm{C} 5 \mathrm{~N} 2) \\
A(\mathrm{C} 5 \mathrm{~N} 2 \mathrm{H} 10) \\
A(\mathrm{C} 5 \mathrm{~N} 2 \mathrm{H} 11)\end{array}$ & $\begin{array}{l}178.6 \\
111.3 \\
109.3 \\
114.0 \\
113.8\end{array}$ & $\begin{array}{l}178.3 \\
111.0 \\
114.8 \\
114.9 \\
114.7\end{array}$ & $\begin{array}{l}179.1 \\
111.5 \\
109.8 \\
115.3 \\
115.2\end{array}$ & $\begin{array}{l}179.1 \\
112.0 \\
108.0 \\
113.7 \\
114.0\end{array}$ & $\begin{array}{l}178.7 \\
112.0 \\
113.1 \\
115.3 \\
115.3\end{array}$ \\
\hline $\begin{array}{l}A(\mathrm{C} 4 \mathrm{C} 5 \mathrm{~N} 2 \mathrm{H} 10)^{a} \\
A(\mathrm{C} 4 \mathrm{C} 5 \mathrm{~N} 2 \mathrm{H} 11) \\
A(\mathrm{C} 3 \mathrm{C} 4 \mathrm{C} 5 \mathrm{~N} 2) \\
A(\mathrm{H} 7 \mathrm{C} 4 \mathrm{C} 5 \mathrm{~N} 2)\end{array}$ & $\begin{array}{r}-164.5 \\
66.0 \\
64.2 \\
-55.4\end{array}$ & $\begin{array}{r}-64.9 \\
67.6 \\
57.4 \\
-62.7\end{array}$ & $\begin{array}{r}152.5 \\
-73.5 \\
61.0 \\
-59.4\end{array}$ & $\begin{array}{r}73.6 \\
-157.3 \\
179.9 \\
58.7\end{array}$ & $\begin{array}{r}67.2 \\
-67.2 \\
180.0 \\
59.0\end{array}$ \\
\hline
\end{tabular}
degrees.

${ }^{a}$ Angle $=180^{\circ}$ for trans rotamer. 
interaction by a raising of the orbital energies both for the nitrile lone-pair and the orbitals in the triple bond.

The optimized molecular geometries are presented in Table 5. The slight preference of conformation II over I is consistent with the optimized values of the dihedral angle C3C4C5N2 given in the table. In the case of II this angle is found to be $57.4^{\circ}$ i.e. a little smaller than the standard gauche angle of $60^{\circ}$, whereas the values of the corresponding angle in $I$ is $64.2^{\circ}$. This difference is most likely due to a stronger stabilizing $\mathrm{H}$-bond in II as compared to I. It also compensates for a longer $\mathrm{C} 4-\mathrm{C} 5$ bond and a larger $\mathrm{C} 4 \mathrm{C} 5 \mathrm{~N} 2$ angle in II than in $\mathrm{I}$.

The localized orbital diagram reflects the difference in the optimal $\mathrm{C} 4-\mathrm{C} 5$ bond distance and $\mathrm{C} 4 \mathrm{C} 5 \mathrm{~N} 2$ valence angle between conformers II and $\mathrm{V}$ on one side and the remaining ones on the other. In II and V the C4-C5 bond distance is found to be around $2 \cdot 10^{-3} \mathrm{~nm}$ longer than in the other conformers, and the angle C4C5N2 is predicted to be around $5^{\circ}$ larger. The C4-C5 orbital energy is higher for these two conformers. However, this change is compensated for by a corresponding lowering of the $\mathrm{C} 4-\mathrm{H} 6, \mathrm{C} 4-\mathrm{H} 7$ and $\mathrm{C} 5-\mathrm{N} 2$ orbital energies.

Acknowledgement. The author wishes to thank Dr. H. Møllendal, The University of Oslo, for sending data prior to publication.

\section{REFERENCES}

1. Møllendal, H. J. Mol. Struct. 97 (1983) 303, and references therein.

2. Braathen, O.-A., Marstokk, K.-M., and Møllendal, H. Acta Chem. Scand. A 37 (1983) 493.

3. Pulay, P., Theor. Chim. Acta 50 (1979) 299.

4. Pulay, P., Mol. Phys. 17 (1969) 197.

5. Pulay, P., Fogarasi, G., Pang, F., and Boggs, J. E., J. Am. Chem. Soc. 101 (1979) 2550.

6. Ditchfield, R., Hehre, W. J., and Pople, J. A. J. Chem. Phys. 54 (1971) 724.

7. Boys, S. E. In Løwdin, P. O., Quantum Theory of Atoms, Molecules and the Solid State, Academic, N. Y. 1966, p. 253.

8. Radom, L., Lathan, W. A., Hehre, W. J., and Pople, J. A. J. Am. Chem. Soc. 95 (1973) 693.

Received June 1, 1983. 